(c) American Dairy Science Association, 2006.

\title{
Discrimination of Dairy Industry Isolates of the Lactobacillus casei Group
}

\author{
A. R. Desai, ${ }^{\star}$ N. P. Shah, ${ }^{\star}$ and I. B. Powell ${ }^{1}$ \\ *School of Molecular Sciences, Victoria University, PO Box 14428, Melbourne City Mail Centre, Victoria 8001, Australia \\ †Australian Starter Culture Research Centre Limited, 180 Princes Highway, Werribee, Victoria 3030, Australia
}

\begin{abstract}
Lactobacilli are a major part of the microflora of the gut and of many fermented dairy products, and are found in a variety of environments. Lactobacillus casei, Lactobacillus paracasei, Lactobacillus rhamnosus, and Lactobacillus zeae form a closely related taxonomic group within the facultatively heterofermentative lactobacilli. The classification and nomenclature of these bacteria are controversial. In this study, relationships between these species were investigated using type strains and dairy industry isolates examined with DNA-based techniques and conventional carbohydrate use tests. Carbohydrate use patterns gave poor discrimination of some species, but DNA PCR using specific primers targeted to sequences of the $16 \mathrm{~S}$ rRNA gene discriminated 4 types consistent with the currently recognized species. Pulsed-field agarose gel electrophoresis of chromosomal Not $\mathrm{I}$ restriction fragments identified 18 different band patterns from 21 independent Lactobacillus isolates and confirmed the identity of $L$. casei strains from 2 culture collections (CSCC 5203 and ASCC 290), both representing the type strain of $L$. casei. Some isolates were reclassified as $L$. rhamnosus, suggesting that the prevalence of $L$. rhamnosus as a natural component of the microflora of dairy foods and dairy environments has previously been underestimated. These methods can provide a practical basis for discrimination of the species and identification of individual industrial strains.
\end{abstract}

Key words: Lactobacillus casei, Lactobacillus paracasei, Lactobacillus rhamnosus, Lactobacillus zeae

\section{INTRODUCTION}

Strains of Lactobacillus are found in many environments. Four closely related facultatively heterofermentative species (Lactobacillus casei, Lactobacillus paracasei, Lactobacillus rhamnosus, and Lactobacillus zeae)

Received August 22, 2005.

Accepted March 27, 2006.

${ }^{1}$ Corresponding author: powell@ascrc.com.au form a taxonomic group and have historically been difficult to distinguish from each other using traditional methods. Many strains have very similar physiological properties and nutritional requirements and grow under similar environmental conditions.

Strains from this group belong to the normal intestinal flora and potentially have beneficial probiotic effects on human and animal health (Ouwehand et al., 2002), but some strains have been observed to be involved in opportunistic infections (Adams, 1999). Some bacteria of this group are major components of starter cultures for cheeses and yogurts, and are also found naturally in raw milk and in high numbers in matured cheeses, where they contribute to positive and negative aspects of cheese maturation and flavor development (Khalid and Marth, 1990; Fitzsimons et al., 1999).

The classification scheme applied to these bacteria has changed considerably in recent decades. The changes are largely based on improved knowledge of gene sequences, and are intended to make the classification scheme accurately reflect natural bacterial groups and the evolutionary relationships between them. Such changes are entirely sensible to taxonomists and evolutionary biologists but can complicate interpretation of the literature and cause confusion for industrial users of these bacteria and for those marketing or consuming products containing them.

Several DNA homology studies (e.g., Collins et al., $1989)$ resulted in 3 species being recognized ( $L$. casei, L. paracasei, and L. rhamnosus) instead of a single "L. casei" taxon. Within a few years, further studies resulted in the proposal of a new species, L. zeae (Dicks et al., 1996), and in the suggestion (Dicks et al., 1996; Dellaglio et al., 2002) that some strains currently classified as $L$. casei and $L$. zeae should be regarded as the same species (and given the name $L$. zeae) and that many strains currently known as $L$. casei and L. paraca$s e i$ should be reclassified into a single species (and given the name $L$. casei, with the name $L$. paracasei abandoned). The Judicial Commission of the International Committee on Systematics of Prokaryotes has yet to publish an opinion on this proposal (De Vos et al., 2005). The recent literature must be interpreted carefully, because some authors have adopted this new classification 
(e.g., Dellaglio et al., 2002; Dobson et al., 2004) but others have not (e.g., Mori et al., 1997; Ward and Timms, 1999; Vásquez et al., 2005; this study). Commercial strain descriptions often ignore the recommendations of taxonomists, and the classification " $L$. casei" is sometimes loosely applied to strains of any of these species.

In industrial application of lactobacilli, it is important to have tools with which to identify particular strains, to understand the relationships between strains, to monitor the genetic stability of strains, and to classify them into recognizable species with due reference to the current taxonomy of the organisms. As part of broader work on the potential probiotic properties of lactobacilli (Desai et al., 2004), the aims of this study were to examine the effectiveness of carbohydrate fermentation tests, species-specific PCR, and pulsedfield gel electrophoresis (PFGE) of genomic restriction fragments for discriminating food industry strains of the L. casei group.

\section{MATERIALS AND METHODS}

\section{Bacterial Strains}

The bacterial strains used in this study (Table 1) were cultured using de Man, Rogosa, and Sharpe (MRS) broth (static cultures) or MRS agar (Oxoid, Basingstoke, UK) at $37^{\circ} \mathrm{C}$. All strains grew well without the use of anaerobic conditions. Type strains (i.e., recognized reference strains) were included in the study. Species epithets are used in this report in accordance with the 4-species scheme (L. casei, L. zeae, L. paracasei, L. rhamnosus), with cross-reference to the alternative 3-species scheme (L. casei, L. zeae, L. rhamnosus) where appropriate.

\section{Species-Specific PCR}

Polymerase chain reaction primers designed on the basis of ribosomal RNA operon sequences are described in Table 2. Oligonucleotide primers used for PCR were synthesized by Life Technologies (Melbourne, Victoria, Australia). Polymerase chain reactions $(50 \mu \mathrm{L}$, using reagents from Roche Diagnostics, Castle Hill, New South Wales, Australia) were performed in $10 \mathrm{~m} M$ Tris$\mathrm{HCl}$ (pH 8.3), $1.5 \mathrm{mM} \mathrm{MgCl}$, and $50 \mathrm{mM} \mathrm{KCl}$ in the presence of Taq DNA polymerase (1 U), deoxynucleotide triphosphates (200 $\mu M$ each), 2 primers ( $0.5 \mu M$ each), and $1 \mu \mathrm{L}$ of bacterial genomic DNA prepared (by the method of $\mathrm{Pu}$ et al., 2002) from a fresh colony grown on the surface of MRS agar. A PTC thermocycler (MJ Research, Waltham, MA) was used. Initial denaturation was carried out at $94^{\circ} \mathrm{C}$ for 3 min, followed by 30 cycles of $45 \mathrm{~s}$ at $50^{\circ} \mathrm{C}, 60 \mathrm{~s}$ at $72^{\circ} \mathrm{C}$, and $45 \mathrm{~s}$ at $94^{\circ} \mathrm{C}$, with a final product extension for $5 \mathrm{~min}$ at $72^{\circ} \mathrm{C}$. The PCR products were analyzed by $1 \%$ (wt/vol) agarose gel electrophoresis in $0.5 \times$ Tris-borate-EDTA buffer with ethidium bromide $(0.5 \mu \mathrm{g} / \mathrm{mL})$.

\section{Partial 16S rRNA Gene Sequencing}

Polymerase chain reaction products amplified using primers Y1 and Y2 were purified using Wizard columns (Promega, Annandale, New South Wales, Australia) and their sequences determined with ABI PRISM BigDye Terminator (Applied Biosystems, Scoresby, Victoria, Australia) fluorescent dye-terminator chemistry by the Micromon nucleotide sequencing facility (Monash University, Clayton, Victoria, Australia).

\section{PFGE}

Preparation of Genomic DNA in Agarose Blocks. Bacterial genomic DNA was prepared from $1 \mathrm{~mL}$ of MRS broth overnight culture, using a modification of the method of Tanskanen et al. (1990). Cells were harvested centrifugally, washed, and then suspended in $150 \mu \mathrm{L}$ of NaCl-EDTA-Tris solution $(1 \mathrm{M} \mathrm{NaCl}, 10 \mathrm{mM}$ EDTA, $10 \mathrm{~m} M$ Tris-HCl, $\mathrm{pH} 8.0$ ) at $45^{\circ} \mathrm{C}$. The cell suspension was mixed with $200 \mu \mathrm{L}$ of low-melting-temperature agarose $(2.5 \% \mathrm{wt} / \mathrm{vol}$; BioRad Laboratories, Regents Park, New South Wales, Australia) at $45^{\circ} \mathrm{C}$, and then dispensed into molds (Amersham Pharmacia Biotech, Castle Hill, New South Wales, Australia) and allowed to solidify. Cells immobilized in agarose blocks were incubated overnight at $37^{\circ} \mathrm{C}$ in lysis buffer containing $100 \mathrm{~m} M$ EDTA, $1 M \mathrm{NaCl}, 10 \mathrm{~m} M$ Tris-HCl (pH 8.0), $1 \%$ lauroyl-sarcosine, $10 \mathrm{mg} / \mathrm{mL}$ of lysozyme (Sigma, St. Louis, MO), and $30 \mathrm{U} / \mathrm{mL}$ of mutanolysin (Sigma). Treatment with proteinase K $(5 \mathrm{mg} / \mathrm{mL}$; ICN Biochemicals, Seven Hills, New South Wales, Australia) was performed for $4 \mathrm{~d}$ at $42^{\circ} \mathrm{C}$ in $100 \mathrm{~m} M$ EDTA (pH 8.0) and 1\% lauroyl-sarcosine.

Restriction Enzyme Digestion and PFGE. A 1$\mathrm{mm}$ slice was cut from each agarose block using a sterile razor blade. Slices were equilibrated with $1 \mathrm{~m} M$ EDTA, $10 \mathrm{~m} M$ Tris-HCl (pH 8.0) for $1 \mathrm{~h}$, then with 2 changes (45 min each) of NotI restriction enzyme buffer (Roche). Restriction enzyme digestion was carried out with $5 \mathrm{U}$ of $N o t \mathrm{I}$ at $37^{\circ} \mathrm{C}$ for 18 to $20 \mathrm{~h}$.

Electrophoresis was carried out with an LKB Pulsaphor CHEF apparatus (Amersham Pharmacia Biotech) in $1.3 \%$ agarose with $0.5 \times$ Tris-borate-EDTA buffer at $14^{\circ} \mathrm{C}$ and at $290 \mathrm{~V}$. Field pulse times were increased from 1 to $10 \mathrm{~s}$ over $6 \mathrm{~h}$, then from 10 to $20 \mathrm{~s}$ over $4 \mathrm{~h}$. The agarose gel was stained with ethidium bromide $(0.5 \mu \mathrm{g} / \mathrm{mL})$ in $0.5 \times$ Tris-borate-EDTA buffer for $1 \mathrm{~h}$. Then, DNA bands were visualized using 302-nm UV 
Table 1. Bacterial strains used in this study

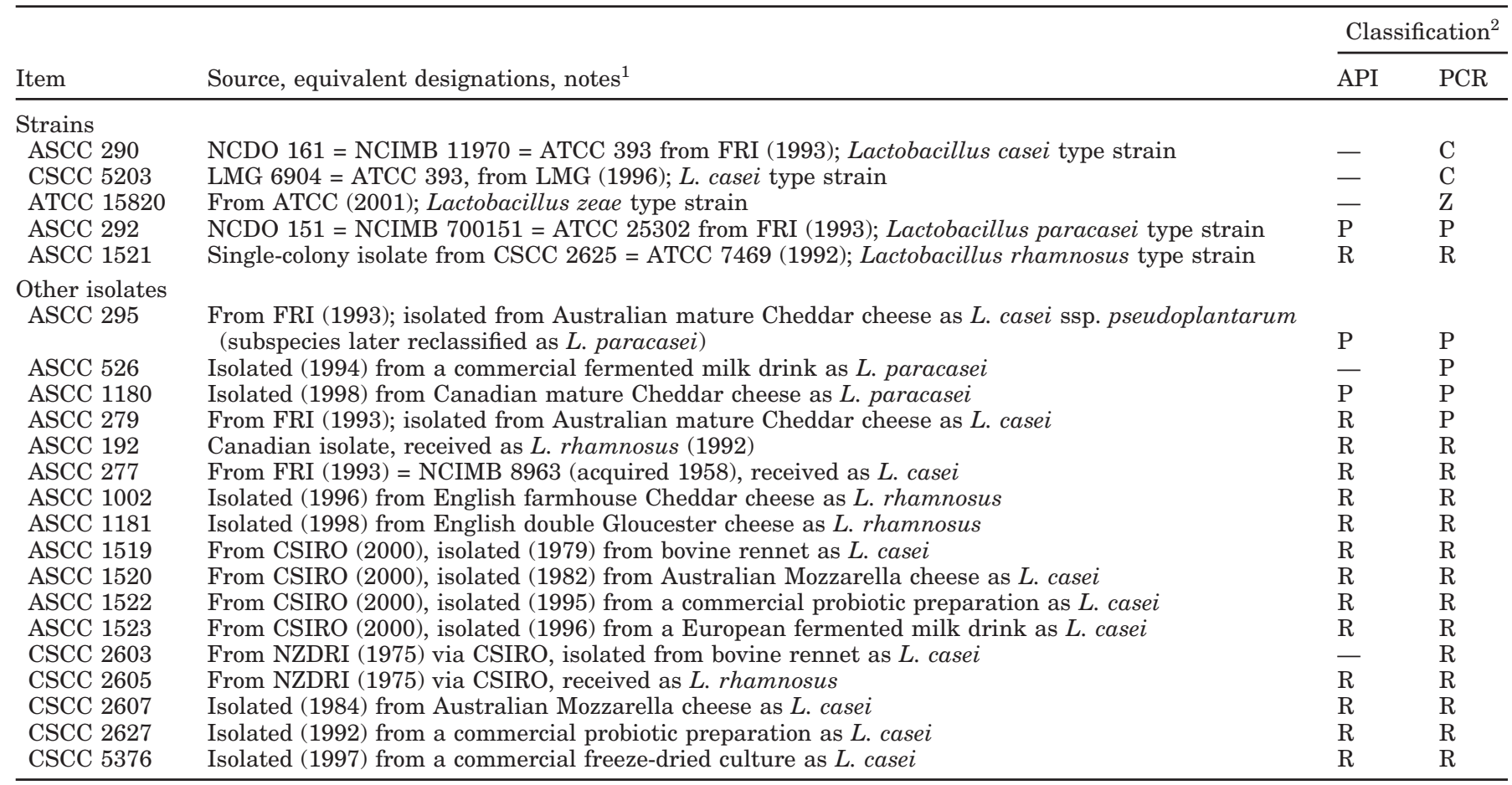

${ }^{1}$ ASCC = Australian Starter Culture Collection, Australian Starter Culture Research Centre (Werribee, Victoria, Australia); ATCC = American Type Culture Collection (Manassas, VA); CSIRO = Commonwealth Scientific and Industrial Research Organisation (Highett, Victoria, Australia); CSCC = CSIRO Starter Culture Collection (Highett, Victoria, Australia); FRI = Food Research Institute, Werribee, Victoria, Australia; LMG = Belgian Coordinated Collections of Microorganisms, Laboratorium Mikrobiologie (Ghent, Belgium); NCDO = National Collection of Dairy Organisms (Shinfield, Berkshire, UK; available through NCIMB); NCIMB = National Collection of Industrial, Marine and Food Bacteria (Bucksburn, Aberdeen, UK); NZDRI = New Zealand Dairy Research Institute (Palmerston North, New Zealand).

${ }^{2}$ Lactobacillus species classification: $\mathrm{C}=$ L. casei, $\mathrm{P}=$ L. paracasei, $\mathrm{R}=$ L. rhamnosus, $\mathrm{Z}=$ L. zeae. API $=$ classification based on API 50CHL test plates. Dashes indicate no classification. PCR = classification based on PCR with primer sets 1 and 2 (Table 2).

transillumination and photographed with a MultiDocIt digital imaging system (UVP, Cambridge, UK). Electrophoretic band patterns were compared by JaccardUPGMA (unweighted pair group method with arithmetic mean) analysis using GelCompar II software (Applied Maths, Sint-Martens-Latem, Belgium) with bandmatching optimization and tolerance settings of $1 \%$.

\section{Carbohydrate Fermentation Tests}

To classify strains biochemically, API 50CHL test plates and APILABplus software with identification database version 4.0 (BioMerieux, Marcy-l'Etoile, France) were used. A further Jaccard-UPGMA analysis was performed on tabulated data using FreeTree 0.9.1.50 (Pav-

Table 2. 16S ribosomal RNA gene PCR primers used in this study

\begin{tabular}{|c|c|c|}
\hline Name & Sequence $5^{\prime}$ to $3^{\prime}$ & Comments, references \\
\hline $\mathrm{Y} 1$ & TGGCTCAGAACGAACGCTAGGCCCG & $\begin{array}{l}\text { "Universal" primer, targets a widely conserved sequence for amplification } \\
\text { from bacterial 16S rRNA gene (Young et al., 1991) }\end{array}$ \\
\hline W1 & TGCACTGAGATTCGACTTAA & Targets the 16S rRNA gene; "casei" primer of Ward and Timmins (1999) \\
\hline W2 & CACCGAGATTCAACATGG & Targets the 16S rRNA gene; "para" primer of Ward and Timmins (1999) \\
\hline \multicolumn{3}{|c|}{ Primer set 2} \\
\hline Rha(F) & CTTGCATCTTGATTTAATTTTG & $\begin{array}{l}\text { Targets Lactobacillus rhamnosus } 16 \mathrm{~S} \text { rRNA gene (Tynkkynen et al., 1999). } \\
\text { Targets the same region as the W3 primer. }\end{array}$ \\
\hline $\operatorname{Rha}(\mathrm{R})$ & CCGTCAATTCCTTTGAGTTT & Targets $L$. rhamnosus $16 \mathrm{~S}$ rRNA gene (Tynkkynen et al., 1999) \\
\hline
\end{tabular}


Table 3. Polymerase chain reaction analysis of Lactobacillus type strains

\begin{tabular}{lllll}
\hline $\begin{array}{l}\text { Primers } \\
\text { used }\end{array}$ & L. casei & L. paracasei & L. rhamnosus & $\begin{array}{l}\text { L. zeae } \\
\text { ATCC 15820 }\end{array}$ \\
\hline W1-Y2 & ASCC 290 & ASCC 292 & ASCC 1521 & - \\
W2-Y2 & + & - & - & - \\
W3-Y2 & - & + & - & - \\
D1-Y2 & - & - & + & + \\
\hline
\end{tabular}

licek et al., 1999) and TreeView 1.6.6 (Page, 1996) software.

\section{RESULTS AND DISCUSSION}

\section{Use of PCR to Distinguish Species}

Polymerase chain reaction primers (Table 2) targeting the 16S rRNA gene and the spacer region between the 16S and 23S rRNA genes were used in this study. Some of these primers had previously been used in limited studies that did not include a full set of species type strains and in which the results of PCR were not corroborated by sequence analysis of the bacterial strains used.

In the present study, a gene region that included the sequences targeted by primers $\mathrm{W} 1, \mathrm{~W} 2, \mathrm{~W} 3$, and D1 was PCR amplified from each of the type strains using the Y1-Y2 primer pair, and the DNA sequence from each strain was determined. Sequences were consistent with relevant GenBank sequence entries AY196978 (ATCC 393), D86517 (ATCC 334), D16552 (ATCC 7469), and D86516 (ATCC 15820).

Polymerase chain reaction was carried out using template DNA from each of the type strains (Table 1) with primer pairs W1-Y2, W2-Y2, W3-Y2, and D1-Y2. In these experiments, the common primer Y2 was used with different specific primers designed on the basis of sequence "signatures" from the V1 region of the $16 \mathrm{~S}$ rRNA gene (Mori et al., 1997; Ward and Timmins, 1999; GenBank D86516). A PCR product of approximately $295 \mathrm{bp}$ was amplified from each type strain, depending which specific primer was used (Table 3 ). It was therefore shown that these primer pairs could distinguish the 4 bacterial type strains.

The same PCR assays were applied to 17 industrial isolates from various sources (Table 1). Most of these strains had been isolated and phenotypically classified by food industry laboratories between the years 1975 and 1998, and ASCC 277 was derived from a strain acquired by the National Collection of Industrial, Marine and Food Bacteria (Bucksburn, Aberdeen, UK in 1958. Ten of these strains had historically been classified as "L. casei," a classification that could at the time have included strains that now would be classified as
L. casei (L. zeae under recent proposals), L. paracasei ( $L$. casei under recent proposals), L. zeae, or L. rhamnosus.

Using the PCR assay, 13 of the 17 strains were classified as $L$. rhamnosus, including 9 of the 10 strains historically described as $L$. casei. Confirmation of the classification of these strains was achieved by testing all strains in PCR with primer pair Rha $(\mathrm{F})-\mathrm{Rha}(\mathrm{R})$ (Table 2). This primer pair and the W3-Y2 pair gave the same classification of $L$. rhamnosus strains (results not shown).

Four strains gave positive PCR with the W2-Y2 primer pair, resulting in classification as $L$. paracasei (L. casei under recent proposals). None of the industry isolates gave positive PCR with primer pairs $\mathrm{W} 1-\mathrm{Y} 2$ or D1-Y2. This is consistent with molecular taxonomic studies that have defined few strains of $L$. casei or $L$. zeae.

\section{PFGE}

Pulsed-field gel electrophoresis of genomic NotI restriction fragments was carried out to discriminate strains at the genetic level. Tynkkynen et al. (1999) used this method and concluded that it was a powerful technique for discriminating L. rhamnosus strains. In their study involving human isolates of L. rhamnosus, they found several isolates to be indistinguishable from probiotic strain L. rhamnosus GG (Saxelin, 1997), perhaps indicating widespread consumption of this commercially produced strain.

In the present study, inspection revealed 18 different NotI restriction fragment patterns from the 21 independent strains studied (Figure 1), showing that most of the strains were genuinely different from each other and distinguishable by this method. This complements the PCR methods used, which distinguished L. paracasei (L. casei under recent proposals) and L. rhamnosus strains at the species level.

Strains ASCC 290 and CSCC 5203 (both representing the type strain of $L$. casei but obtained from independent sources) showed identical fragment patterns, consistent with their recorded identity. Strains ASCC 1523 and CSCC 2627 also gave indistinguishable patterns, but no common origin for these strains is known. The patterns were also indistinguishable for strains ASCC 

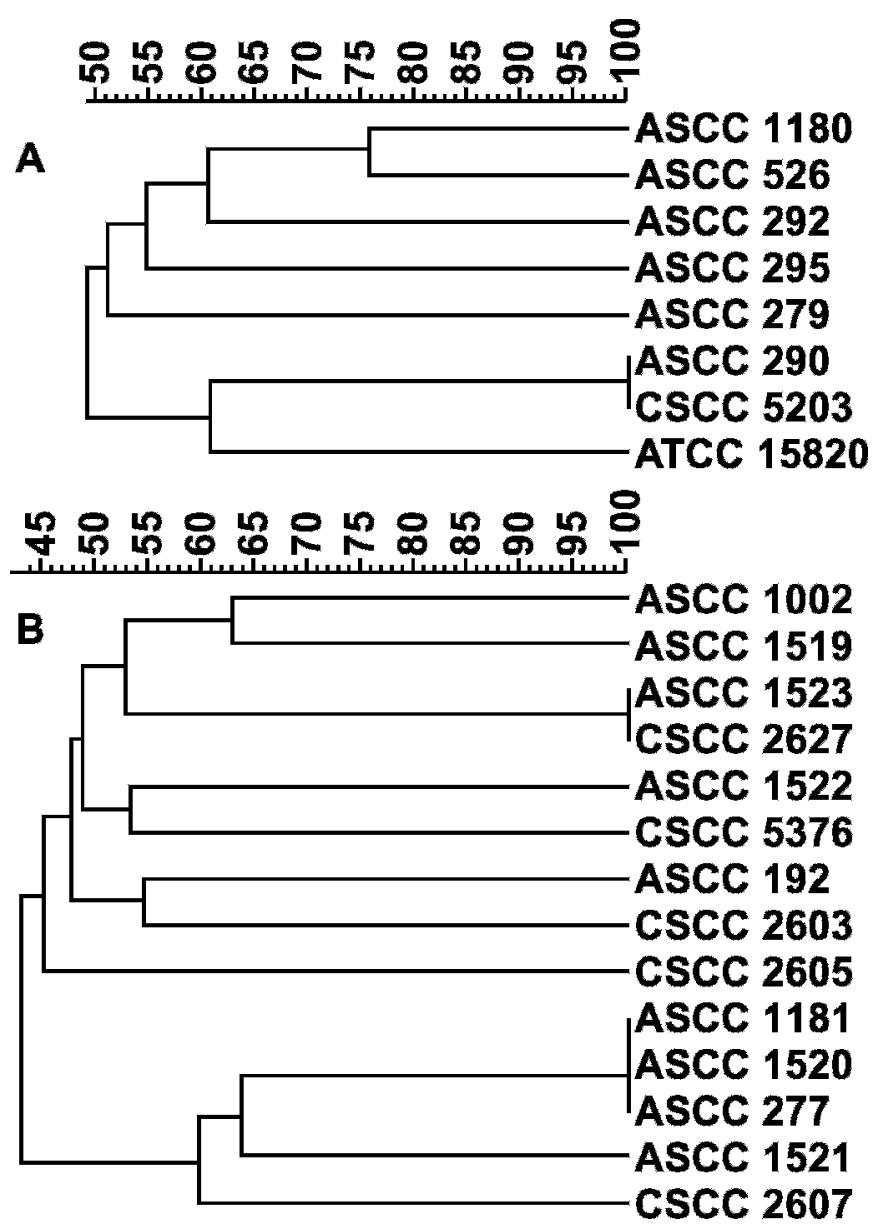

Figure 1. Dendrograms derived from the UPGMA (unweighted pair group method with arithmetic mean) analysis of Jaccard similarities in NotI genomic fragment patterns obtained in pulsed-field gel electrophoresis. The similarity scale (\%) is shown: (A) Lactobacillus paracasei, Lactobacillus casei, and Lactobacillus zeae; (B) Lactobacillus rhamnosus. ASCC = Australian Starter Culture Collection, Australian Starter Culture Research Centre (Werribee, Victoria, Australia); CSCC = Commonwealth Scientific and Industrial Research Organisation (CSIRO) Starter Culture Collection (Highett, Victoria, Australia); ATCC = American Type Culture Collection (Manassas, VA).

277, ASCC 1181, and ASCC 1520. One of these (ASCC 277 = NCIMB 8963) has long been available from a commercial culture collection.

Comparison of small-fragment restriction enzyme patterns was previously shown to give a useful species distinction of $L$. paracasei from $L$. rhamnosus and of the $L$. zeae type strain from other species, but the $L$. casei type strain could not be distinguished from $L$. rhamnosus (Vásquez et al., 2005). In the present study using large-fragment PFGE (with an enzyme chosen because it shows differences between strains), the species could not be separated (data not shown). However, after using PCR to make a species assignment, pattern similarities (close strain relationships) within L. rhamnosus were readily identified (Figure 1B) and the distinction of $L$. paracase $i$ strains and the type strains of $L$. casei and $L$. zeae could be achieved (Figure 1A). The similarity index (Figure 1) indicates that $L$. casei and L. zeae are perhaps no more distant from each other than are some strains within $L$. paracasei or $L$. rhamnosus.

\section{Biochemical Classification}

Biochemical identification results from API 50CHL testing are shown in Table 1. Lactobacillus paracasei (L. casei under recent proposals) and L. rhamnosus classifications were consistent with classifications from the PCR assays with one clear exception (ASCC 279). The internal quality assessment feature of the API software judged 2 classifications (ASCC 526 and CSCC 2603) as "unacceptable," implying that the pattern analysis software was unable to make a clear classification. Neither $L$. casei nor $L$. zeae is classifiable using the API proprietary database and software, presumably because few strains have been available for study. The $L$. casei and $L$. zeae type strain fermentation patterns differed from typical $L$. paracasei fermentation patterns by 6 to 9 sugars fermented or not fermented, and by 5 sugars from each other. Even so, Jaccard-UPGMA analysis of the fermentation test results was also unable to separate these strains from the other species or from each other (not shown). Such observations illustrate the limitations of biochemical profiling when applied to closely related bacteria with intraspecies heterogeneity.

\section{Taxonomic Considerations}

The phylogenetic relationships between the various bacteria of this group are generally not in dispute, but there is debate over where species boundaries should be drawn and what names should be attached to those species. The results of this study are consistent with the prevailing view that 1 ) L. rhamnosus is a common and readily distinguishable species, 2) a second common and readily distinguishable species exists, herein referred to as $L$. paracasei, but proposed by some (Dellaglio et al., 2002) to be known as $L$. casei, and 3) relatively uncommon types also exist. These $L$. casei- $L$. zeae types are undoubtedly closely related to each other (Mori et al., 1997; Dobson et al., 2004; Vásquez et al., 2005), plausibly justifying reclassification of these bacteria into a single species (Dellaglio et al., 2002).

At the heart of the nomenclature debate is the proposal to reclassify the type strain of L. casei (ATCC 393 and equivalents, in this study ASCC 290 and CSCC 
5203) as L. zeae. Species are conventionally defined largely in terms of their type strains, and so this reclassification would be a highly unusual step. The phylogenetic relationships could equally be accommodated by merging $L$. casei and $L$. zeae under the name $L$. case $i$ (with ATCC 393 as the type strain) and reclassifying some strains currently held in collections as $L$. casei to L. paracasei. This would not involve the controversial act of removing a type strain from its species.

\section{Practical Species and Strain Discrimination}

Mori et al. (1997) proposed that the sequences of $16 \mathrm{~S}$ rRNA genes could distinguish species within the $L$. casei group, and they established "signature" sequence features that could be used as PCR targets for speciesspecific product amplification (e.g., Ward and Timmins, 1999). This approach has been extended in the present work to permit 4 groups to be discriminated. Polymerase chain reaction conditions (particularly the annealing temperature; data not shown) are crucial to achieving clear discrimination, and might require adjustment for use with different PCR reaction mixes or thermal cycling devices. The use of 4 separate PCR reactions (plus a negative control to which no template DNA is added) provides a set of positive-negative test results that are easily interpreted and that provide immediate confirmation of PCR specificity or of any cross-reaction. The methods used in this study (PCR followed by electrophoresis) are now available to many food laboratories, and the ease of interpretation is a considerable advantage over conventional tests such as fermentation pattern analysis. The species-specific primers could also form the basis of a "probe oligonucleotide" set for use in a single-tube quantitative PCR assay using fluorescence-detection real-time PCR. The positive-negative aspect of the test would also be a useful confirmation of specificity in a real-time assay system.

The combination of 4-reaction PCR and PFGE is a workable approach for strain classification and identification, but the results must be interpreted carefully. The results obtained in this study are consistent with the conclusions of Mori et al. (1997), Ward and Timmins (1999), and Vásquez et al. (2001) that L. paracasei and $L$. rhamnosus could readily be identified and that $L$. casei could be distinguished from $L$. zeae on the basis of aspects of their 16S rRNA gene sequences. Both are readily distinguished from $L$. paracase $i$ and $L$. rhamnosus. However, Vásquez et al. (2005) reported a more detailed sequence analysis showing that the multiple copies of the 16S rRNA gene within a single strain are not always identical. Notably, intrastrain sequence heterogeneity was observed within the type strains of $L$. casei, $L$. paracasei, and $L$. zeae. Interstrain sequence polymorphism was observed within these species and within L. rhamnosus, further complicating interpretation of available sequence data and identification of unambiguous signature sequences. Some of this heterogeneity is within the region targeted by the primers W1, W2, W3, and D1 (at positions 96, 97, 99, 105, and 110 as described by Vásquez et al., 2005). The results of the present study suggest this heterogeneity does not interfere with the PCR-based classification of strains of $L$. paracasei and L. rhamnosus, nor does it interfere with distinguishing between the type strains of $L$. case $i$ and $L$. zeae. The full extent of inter- and intrastrain heterogeneity within the latter species (whether they are regarded as 2 species or merged into a single species) is not known because so few strains have been studied. It is possible that the primers $\mathrm{W} 1$ and $\mathrm{D} 1$ target only 2 of many possible sequence variants. Evaluation with other strains would be required to ensure that no problems existed, but the multiple positive-negative aspect of the test scheme would alert the experimenter to any cross-reactions that might occur.

\section{Reclassification of Archive Isolates}

Strains described in the historical literature or held in archival collections require reexamination and possible reclassification before they can properly be described and compared with recent isolates and the recent literature. In this study, 9 strains historically described as $L$. casei were reclassified as $L$. rhamnosus.

Ward and Timmins (1999) examined "L. casei group" isolates from cheeses and reported $L$. rhamnosus and a preponderance of $L$. paracasei, but no $L$. casei. The isolates tested in the present study came from cheeses but also from a range of noncheese sources, with $L$. rhamnosus as the most common species. Considered together, these studies indicate that $L$. casei (as currently defined) is not common in dairy environments or in dairy manufacturing. Lactobacillus paracasei and L. rhamnosus are the common cheese isolates from the L. casei group and, in this study, L. rhamnosus was identified from cultures and other dairy sources.

\section{CONCLUSIONS}

In this study, we confirmed that a set of simple PCR tests based on 16S rRNA gene sequences, coupled with PFGE, can be used to distinguish Lactobacillus strains of the $L$. casei group. The usefulness of sugar fermentation tests is limited to identification of $L$. paracase $i$ and $L$. rhamnosus. The results indicate that $L$. casei and $L$. zeae are not common in dairy environments and that (at least within the collection studied) the prevalence of $L$. rhamnosus has been historically underestimated. 
Reclassification of strains described in the literature and in industry practice is recommended.

\section{ACKNOWLEDGMENTS}

The Australian Starter Culture Research Centre (ASCRC) acknowledges ongoing support from Dairy Australia (Southbank, Victoria, Australia). Thanks to Anita Chu for assistance with strains from ASCRC and the Commonwealth Scientific and Industrial Research Organisation (Highett, Victoria, Australia) collections.

\section{REFERENCES}

Adams, M. R. 1999. Safety of industrial lactic acid bacteria. J. Biotechnol. 68:171-178.

Collins, M. D., B. A. Phillips, and P. Zanoni. 1989. Deoxyribonucleic acid homology studies on Lactobacillus casei, Lactobacillus paracasei sp. nov. subsp. paracasei and subsp. tolerans, and Lactobacillus rhamnosus sp. nov., comb. nov. Int. J. Syst. Bacteriol. 39:105-108.

Dellaglio, F., G. E. Felis, and S. Torriani. 2002. The status of the species Lactobacillus casei (Orla-Jensen 1916) Hansen and Lessel 1971 and Lactobacillus paracasei Collins et al. 1989. Request for an opinion. Int. J. Syst. Evol. Microbiol. 52 (Pt. 1):285-287.

Desai, A. R., I. B. Powell, and N. P. Shah. 2004. Survival and activity of probiotic lactobacilli in skim milk containing prebiotics. J. Food Sci. 69:FMS57-FMS60.

Dicks, L. M. T., E. M. DuPlessis, F. Dellaglio, and E. Lauer. 1996. Reclassification of Lactobacillus casei subsp. casei ATCC 393 and Lactobacillus rhamnosus ATCC 15820 as Lactobacillus zeae nom. rev., designation of ATCC 334 as the neotype of L. casei subsp. casei, and rejection of the name Lactobacillus paracasei. Int. J. Syst. Bacteriol. 46:337-340.

De Vos, P., H. G. Trüper, and B. J. Tindall. 2005. Judicial Commission of the International Committee on Systematics of Prokaryotes, Xth International Congress of Bacteriology and Applied Microbiology, minutes of meetings 28, 29 and 31 July and 1 August 2002, Paris, France. Int. J. Syst. Evol. Microbiol. 55:525-532.

Dobson, C. M., B. Chaban, H. Deneer, and B. Ziola. 2004. Lactobacillus casei, Lactobacillus rhamnosus, and Lactobacillus zeae isolates identified by sequence signature and immunoblot phenotype. Can. J. Microbiol. 50:482-488.

Fitzsimons, N. A., T. M. Cogan, S. Condon, and T. Beresford. 1999. Phenotypic and genotypic characterization of non-starter lactic acid bacteria in mature cheddar cheese. Appl. Environ. Microbiol. 65:3418-3426.

Khalid, N. M., and E. H. Marth. 1990. Lactobacilli-Their enzymes and role in ripening and spoilage of cheese: A review. J. Dairy Sci. 73:2669-2684.

Mori, K., K. Yamazaki, T. Ishiyama, M. Katsumata, K. Kobayashi, Y. Kawai, N. Inoue, and H. Shinano. 1997. Comparative sequence analyses of the genes coding for 16S rRNA of Lactobacillus caseirelated taxa. Int. J. Syst. Bacteriol. 47:54-57.

Ouwehand, A. C., S. Salminen, and E. Isolauri. 2002. Probiotics: An overview of beneficial effects. Antonie Van Leeuwenhoek 82:279-289.

Page, R. D. M. 1996. TreeView: An application to display phylogenetic trees on personal computers. Comput. Appl. Biosci. 12:357-358.

Pavlicek, A., S. Hrda, and J. Flegr. 1999. FreeTree-Freeware program for construction of phylogenetic trees on the basis of distance data and bootstrap/jackknife analysis of the tree robustness. Application in the RAPD analysis of the genus Frenkelia. Folia Biol. (Praha) 45:97-99.

Pu, Z. Y., M. Dobos, G. K. Y. Limsowtin, and I. B. Powell. 2002. Integrated polymerase chain reaction-based procedures for the detection and identification of species and subspecies of the Grampositive bacterial genus Lactococcus. J. Appl. Microbiol. 93:353-361.

Saxelin, M. 1997. Lactobacillus GG-A human probiotic strain with thorough clinical documentation. Food Rev. Int. 13:293-313.

Tanskanen, E. I., D. L. Tulloch, A. J. Hiller, and B. E. Davidson. 1990. Pulsed-field gel electrophoresis of SmaI digests of lactococcal genomic DNA, a novel method of strain identification. Appl. Environ. Microbiol. 56:3105-3111.

Tynkkynen, S., R. Satokari, M. Saarela, T. Mattila-Sandholm, and M. Saxelin. 1999. Comparison of ribotyping, randomly amplified polymorphic DNA analysis, and pulsed-field gel electrophoresis in typing of Lactobacillus rhamnosus and L. casei strains. Appl. Environ. Microbiol. 65:3908-3914.

Vásquez, A., S. Ahrné, B. Pettersson, and G. Molin. 2001. Temporal temperature gradient gel electrophoresis (TTGE) as a tool for identification of Lactobacillus casei, Lactobacillus paracasei, Lactobacillus zeae, and Lactobacillus rhamnosus. Lett. Appl. Microbiol. 32:215-219.

Vásquez, A., G. Moran, B. Pettersson, M. Antonsson, and S. Ahrné 2005. DNA-based classification and sequence heterogeneities in the 16S rRNA genes of Lactobacillus casei/paracasei and related species. Syst. Appl. Microbiol. 28:430-441.

Ward, L. J. H., and M. J. Timmins. 1999. Differentiation of Lactobacillus casei, Lactobacillus paracasei, and Lactobacillus rhamnosus by polymerase chain reaction. Lett. Appl. Microbiol. 29:90-92.

Young, J. P., H. L. Downer, and B. D. Eardly. 1991. Phylogeny of the phototrophic Rhizobium strain BTAi1 by polymerase chain reaction-based sequencing of a $16 \mathrm{~S}$ rRNA gene segment. J. Bacteriol. 173:2271-2277. 